\section{(6) OPEN ACCESS}

\title{
Recent advances in genetically modified animal models of glaucoma and their roles in drug repositioning
}

\author{
Chikako Harada, Atsuko Kimura, Xiaoli Guo, Kazuhiko Namekata, Takayuki Harada
}

Visual Research Project, Tokyo Metropolitan Institute of Medical Science, Tokyo 1568506, Japan

\section{Correspondence to}

Professor Takayuki Harada, Visual Research Project, Tokyo Metropolitan Institute of Medical Science, Tokyo 156-8506, Japan; harada-tk@ igakuken.or.jp

Received 12 June 2018 Revised 21 August 2018 Accepted 25 August 2018 Published Online First 26 October 2018

\section{Check for updates}

(C) Author(s) (or their employer(s)) 2019. Re-use permitted under CC BY-NC. No commercial re-use. See rights and permissions. Published by BMJ.

To cite: Harada C, Kimura A, Guo X, et al. Br J Ophthalmol 2019;103:161-166.

\section{ABSTRACT}

Glaucoma is one of the leading causes of vision loss in the world. Currently, pharmacological intervention for glaucoma therapy is limited to eye drops that reduce intraocular pressure (IOP). Recent studies have shown that various factors as well as IOP are involved in the pathogenesis of glaucoma, especially in the subtype of normal tension glaucoma. To date, various animal models of glaucoma have been established, including glutamate/ aspartate transporter knockout (KO) mice, excitatory amino acid carrier $1 \mathrm{KO}$ mice, optineurin E50K knock-in mice, DBA/2J mice and experimentally induced models. These animal models are very useful for elucidating the pathogenesis of glaucoma and for identifying potential therapeutic targets. However, each model represents only some aspects of glaucoma, never the whole disease. This review will summarise the benefits and limitations of using disease models of glaucoma and recent basic research in retinal protection using existing drugs.

\section{INTRODUCTION}

Glaucoma is a neurodegenerative disease of the eye which involves degeneration of retinal ganglion cells (RGCs) and their axons, namely, the optic nerve. It is the second leading cause of blindness, ${ }^{12}$ and with the current growth in the ageing population, one expects a robust increase in patients with glaucoma, resulting in an urgent need for a cure for this disease. It is estimated that by 2020 , more than 80 million people will be affected worldwide. ${ }^{3}$ The factors associated with the pathogenesis of glaucoma include high intraocular pressure (IOP), ageing, ${ }^{4}$ decreased blood flow, ${ }^{5}$ oxidative stress, ${ }^{6-9}$ glutamate neurotoxicity, ${ }^{10} 11$ decreased trophic factors, ${ }^{12}$ low cerebrospinal fluid pressure, ${ }^{13}$ myopia, ${ }^{14}$ eye movements ${ }^{15}$ and susceptibility genes, such as optineurin and myocilin (figure 1). ${ }^{16}$ Currently, pharmacological intervention for glaucoma therapy is limited to eye drops that reduce IOP. Recently, a concept of neuroprotection against RGC death induced by multiple disease pathogenesis as well as IOP lowering is receiving a lot of attention. ${ }^{11} 17-19$ However, the development of a new drug can take an enormous amount of time, money and effort. One alternative to this is an approach known as drug repositioning, which is the application of an existing drug to a different disease. The beneficial effects of drug repositioning are immense because the drug has already gone through vigorous toxicity and other tests required for bringing a drug to market; thus, it saves vast amounts of time and money. Basic research using animal models of glaucoma has shown some beneficial effects of such existing drugs in neuroprotection. ${ }^{20-24}$ These results suggest the possibility that drug repositioning is a safe and cost-effective approach for the treatment of glaucoma.

\section{ANIMAL MODELS OF GLAUCOMA}

In preclinical research, animal models of glaucoma have contributed greatly to understanding glaucoma pathology and examining potential therapeutic candidates. There are several experimentally induced animal models, ${ }^{25} 26$ such as a simple acute optic nerve crush, ${ }^{27}$ intraocular injection of excitotoxic agents such as $\mathrm{N}$-methyl-D-aspartate (NMDA), ${ }^{28}$ anterior chamber injection of sterile saline at high pressure, ${ }^{29}$ microbead injection, ${ }^{30}$ episcleral vein injection of hypertonic saline ${ }^{31}$ or external laser photocoagulation. ${ }^{32}$ In addition, there are several inherited animal models of high IOP glaucoma (table 1$).^{26}{ }^{33}$ For example, the $\mathrm{DBA} / 2 \mathrm{~J}$ mouse is an age-dependent, inherited model of a high IOP glaucoma with many similarities to the human disease. ${ }^{34}$ The DBA/2J mice develop anterior segment anomalies, iris atrophy, peripheral anterior synechiae and pigment dispersion, leading to an elevated IOP, and they are used in many studies worldwide. However, the model presents significant challenges for drug studies in glaucoma, as there are many confounding factors: difficulty with accurate IOP measurement due to corneal calcification, in vivo imaging and electrophysiology recording due to poor pupil dilation and $22 \%$ of the animals developed major systemic complications leading to a high dropout rate. ${ }^{35}$ In addition, there may be an underlying neurodegenerative process independent of IOP. ${ }^{36}$ For example, approximately $8 \% \sim 10 \%$ of the older DBA/2J mice had one normal, non-diseased retina and optic nerve, and one eye had undergone complete degeneration. ${ }^{25}$ Nevertheless, DBA/2J mice made significant contribution to advances in glaucoma research and served as a valuable tool for translational research in glaucoma. ${ }^{24} 37$ Recently, a study reported ameliorated optic nerve degeneration in transgenic mice overexpressing Norrin crossed with $\mathrm{DBA} / 2 \mathrm{~J}$ mice (DBA/2J/Pax6-Norrin mice), providing a possible therapeutic target for glaucoma. $^{38}$ Norrin is a secreted signalling molecule activating the $\mathrm{Wnt} / \beta$-catenin pathway and protects retinal neurons after NMDA injection, ${ }^{39}$ suggesting that an activator of Norrin and its downstream 


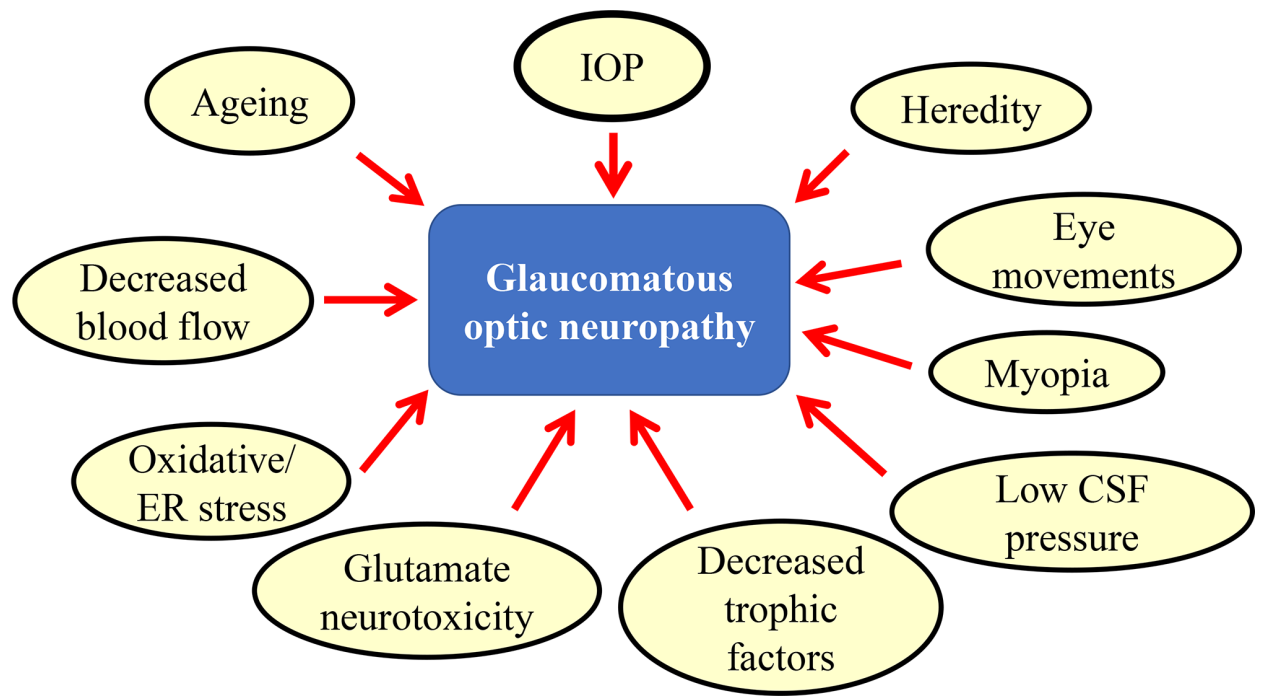

Figure 1 Multiple factors that are involved in the onset/progression of glaucoma. CSF, cerebrospinal fluid; ER, endoplasmic reticulum; IOP, intraocular pressure.

signalling might be useful to prevent glaucomatous damage in human patients.

Other high IOP glaucoma models include Vav2/3 and Vav2-deficient mice that show ocular hypertension due to ocular anterior chamber abnormalities and, consequently, cause glaucomatous optic neuropathy. ${ }^{40}$ Although high IOP and enlarged eyeballs are not detected in all mice, Vav-deficient mice may serve as a valuable animal model of spontaneous ocular hypertension. We recently reported that the purinergic $\mathrm{P} 2 \mathrm{Y}_{6}$ receptor is critical for lowering IOP and that ablation of the $\mathrm{P}^{6} \mathrm{Y}_{6}$ gene in mice $\left(\mathrm{P}_{2} \mathrm{Y}_{6} \mathrm{KO}\right)$ results in hypertensive glaucoma-like optic neuropathy. ${ }^{41}$ Topically applied uridine diphosphate, an endogenous selective agonist for the $\mathrm{P} 2 \mathrm{Y}_{6}$ receptor, decreases IOP. The $\mathrm{P}_{2} \mathrm{Y}_{6}$ receptor is expressed in the non-pigmented epithelial cells of the ciliary body, and its activation results in suppression of the aqueous humour production. $\mathrm{P}_{2} \mathrm{Y}_{6} \mathrm{KO}$ mice exhibited sustained IOP elevation, age-dependent RGC damage and impairment in visual functions, which are similar to the phenotypes of hypertensive glaucoma. We also found that the expression and function of $\mathrm{P} 2 \mathrm{Y}_{6}$ receptors in wild-type mice was significantly reduced by ageing, another important risk factor for glaucoma (figure 1). These data suggest that dysfunctional purinergic signalling causes IOP dysregulation, resulting in glaucomatous optic neuropathy, and the $\mathrm{P}_{2} \mathrm{Y}_{6}$ receptor may be a target for the treatment of glaucoma.

Recent studies have reported that there is an unexpectedly high prevalence of normal tension glaucoma (NTG), a subset of glaucoma that is not associated with increased IOP, especially in Japan and other Asian countries. ${ }^{42} 43$ Interestingly, IOP-unrelated genetic mutations have been found in NTG, and the optineurin E50K mutation was the first one identified in familial NTG. ${ }^{44}$ Optineurin is a multifunctional protein, and its mutations are associated with neurodegenerative diseases, such as primary open-angle glaucoma (POAG) and amyotrophic lateral sclerosis (ALS). ${ }^{45}$ It is reported that an E50K mutation-carrying transgenic mouse shows RGC loss and the reduction of retinal thickness from 12 to 16 months of age under normal IOP. $^{46}$ Transgenic mice with global overexpression of high levels of the E50K mutant optineurin showed a diffuse loss of photoreceptors and non-RGCs, features not observed in POAG. ${ }^{46} 47$ This phenotype of E50K mutant was improved in another E50K transgenic mouse, in which the overexpression was lower and was driven by an optineurin promoter, ${ }^{48}$ and in E50K knock-in mice. ${ }^{49}$ At the molecular level, the E50K mutant strongly interacted with TANK-binding kinase 1 (TBK1), which prohibited the proper oligomerisation and solubility of optineurin, both of which are important for the intracellular transition of optineurin. ${ }^{50}$ These findings suggest that alternation of the optineurin sequence can initiate significant retinal degeneration in mice. This model mimics the gene mutation that is detected in patients with glaucoma, but one problem is that mutations in glaucoma-associated genes, including optineurin, myocilin and CYP1B1, account for about $10 \%$ of cases worldwide. ${ }^{51-53}$ Thus, more applicable models that are not necessarily associated with

Table 1 Genetic models of glaucoma

\begin{tabular}{lllll}
\hline & IOP & Incidence & \multicolumn{2}{l}{ Onset and duration of RGC } \\
& degeneration & Characteristics \\
\hline DBA/2J & High & Dependent on colonies & $8 \sim 15$ months & Region specific RGC loss and systemic complications \\
Vav2/3 KO & High & Almost 75\% 25 34-38 & $3 \sim 8$ months & Buththalmos \\
P2Y 6 KO & High (POAG) & $100 \%$ & $6 \sim 13$ months & Enhanced production of aqueous humour \\
Optineurin E50K knock-in & Normal & $100 \%$ & $3 \sim 12$ months & Same as human genetic mutation \\
EAAC1 KO & Normal & $100 \%$ & $1 \sim 3$ months & Early onset and short disease course \\
GLAST KO & Normal & $100 \%$ & KO: 3 5 weeks & Decrease in glutathione concentration in the retina and 22 54 68 70 80 \\
& & & Heterozygous: 1 4 months & increased oxidative stress
\end{tabular}

EAAC1, excitatory amino acid carrier 1; GLAST, glutamate/aspartate transporter; IOP, intraocular pressure; KO, knockout; POAG, primary open-angle glaucoma; RGC, retinal ganglion cell. 
glaucoma-associated genes, but can cover a wider range of the NTG population, are required (figure 1).

We previously discovered that deletion of the glutamate transporters, glutamate/aspartate transporter (GLAST) or excitatory amino acid carrier 1 (EAAC1) exhibits spontaneous RGC death and optic nerve degeneration without elevation of the IOP, pathology that is similar to NTG. ${ }^{54}$ GLAST is expressed in Müller glia in the retina and clears excess glutamate from the synapse, thus preventing excitotoxic damage on surrounding retinal neurons. ${ }^{29}$ We now understand that the glutamate concentration is not upregulated in the vitreous of patients with glaucoma, but glutamate neurotoxicity may still be involved in the pathology of glaucoma as GLAST expression levels may be decreased with ageing, especially in patients with glaucoma. ${ }^{55-58}$ Glutamate neurotoxicity may also be involved in the RGC loss in DBA/2J mice. ${ }^{5960}$ In addition, glutamate, which is transported into Müller glia by the glutamate uptake process, together with cysteine and glycine, is converted to glutathione (GSH), a major antioxidant in the retina. ${ }^{61}$ Increased oxidative stress is one of the risk factors in glaucoma (figure 1) and, consistently, the plasma GSH level is decreased in patients with glaucoma. ${ }^{67}$ In GLAST knockout (KO) mice, decreased glutamate uptake into the Müller glia leads to reduced GSH production, ${ }^{54}$ indicating that GLAST KO mice exhibit the key pathological features of NTG as a result of chronic glutamate neurotoxicity and increased oxidative stress, which are independent of glaucoma-associated genes. On the other hand, EAAC1 is mainly localised to RGCs, and cultured RGCs from EAAC1 KO mice are more susceptible to $\mathrm{H}_{2} \mathrm{O}_{2}$ insults compared with wild-type RGCs. In addition, oxidative stress markers in EAAC1 $\mathrm{KO}$ mice are significantly higher than those in wild-type mice. ${ }^{5462} 63$ Recent large-scale association analysis in a Japanese population showed the genetic link between POAG and myocardial infarction and ischaemic stroke. ${ }^{64}$ Since both oxidative stress and glutamate neurotoxicity are involved in the pathogenesis of various neurodegenerative diseases and neurological dysfunction, including ischaemic conditions, ${ }^{65}$ GLAST/EAAC1 KO mice seem to reproduce some aspects of sporadic, age-dependent NTG pathology. However, there are some limitations to using these mouse models. For example, the RGC loss in GLAST/EAAC1 KO mice is distributed across the entire retina, rather than in specific regions, as seen in human glaucoma and in some mouse models of ocular hypertension-induced glaucoma ${ }^{66}{ }^{67}$ and retinal degeneration in these mice starts at 3 5 weeks of age, an earlier and faster time-course than one may expect in human glaucoma. Despite some limitations, these mice all develop NTG-like phenotypes in a consistent time course without affecting non-RGCs ${ }^{54} 63$ and have been providing useful information regarding NTG therapy easily and quickly (table 1 ). In addition, RGC degeneration in GLAST heterozygous mice occurs slowly (postnatal $1 \sim 4$ months), and this strain was available for 1 year to test the effects of a new drug. ${ }^{568}$ We recently reported that some widely prescribed drugs suppressed RGC death in GLAST/EAAC1 KO mice without altering IOP. We will summarise these findings in the following section.

\section{EFFECTS OF EXISTING DRUGS ON GLAUCOMA MODEL MICE}

At present, glaucoma cannot be cured, but it can be treated. For example, there are many eye drops that suppress IOP elevation, and some of them may have additional neuroprotective effects, ${ }^{6369}$ but some patients do not respond to this type of treatment. It is a better option for patients if we could prevent or delay glaucomatous neurodegeneration using existing drugs. For example, we recently reported that widely prescribed drugs, such as candesartan, ${ }^{21}$ valproic acid ${ }^{22}$ and geranylgeranylacetone (GGA), ${ }^{70}$ may have neuroprotective effects and preserve visual function in genetically modified animal models of glaucoma (table 2). Candesartan is an angiotensin II receptor antagonist, which is clinically used for the treatment of hypertension, and it has demonstrated neuroprotective effects by suppressing the upregulation of Toll-like receptor 4 (TLR4) in EAAC1 KO mice. ${ }^{21}$ Since TLR4 polymorphisms are associated with NTG ${ }^{7172}$ targeting TLR4 may be a promising strategy for the treatment of glaucoma. Valproic acid is a short-chain fatty acid, which acts as an epigenetic modifier by inhibiting histone deacetylases, and it is already established for use in treatment of epilepsy and others. Treatment with valproic acid improved visual fields in patients with retinitis pigmentosa, and data from a pilot study are encouraging. ${ }^{73} 74$ Valproic acid may also have therapeutic

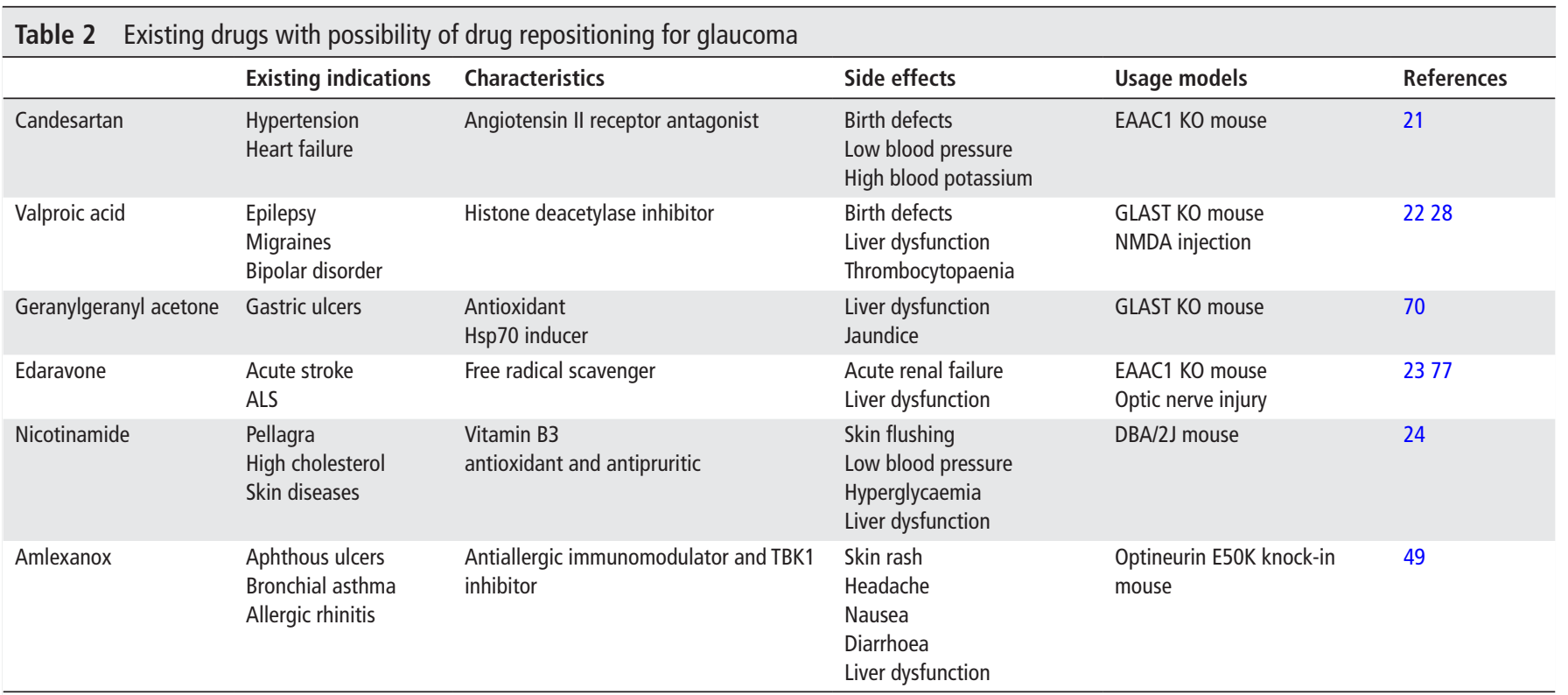

ALS, amyotrophic lateral sclerosis; EAAC1, excitatory amino acid carrier 1; GLAST, glutamate/aspartate transporter; Hsp70, heat shock protein 70; KO, knockout; NMDA, N-methylD-aspartate; TBK1, TANK-binding kinase 1. 
effects in glaucoma as it prevented RGC degeneration in GLAST KO mice by inhibiting the oxidative stress level in RGCs and stimulating the neurotrophic factor signalling. ${ }^{22}{ }^{28}$ Since valproic acid may promote survival and differentiation of human iPS cells, ${ }^{75}$ this drug may be useful for transplantation therapy using iPS cells and/or iPS cell-derived RGCs to replace the degenerated $\mathrm{RGCs}^{76}$ and benefit patients with glaucoma, as well as retinitis pigmentosa. In addition, GGA, which is used for treatment of gastric ulcers, can act as an antioxidant by directly inducing the cytoprotective heat shock protein 70 (Hsp70) expression. Oral administration of GGA also induced Hsp70 expression in the retina and suppressed RGC death in GLAST KO mice. ${ }^{70}$ Therefore, targeting to reduce oxidative stress in the retina may be a novel therapeutic strategy for glaucoma. ${ }^{9}$ We recently examined the effects of edaravone, a free radical scavenger, which is used for treatment of acute brain infarction and ALS, and found that this drug reduced oxidative stress and prevented RGC death in EAAC1 $\mathrm{KO}$ mice. ${ }^{23}$ In addition, the intraocular injection of edaravone just after optic nerve injury (ONI) exerted neuroprotective effects by suppressing the production of reactive oxygen species and the stress-induced signalling of apoptosis signal-regulating kinase 1 (ASK1). ${ }^{77}$ The ASK1-p38 mitogen-activated protein kinase (MAPK) pathway is activated in response to multiple types of stress, and it is implicated in diseases such as cancer, Alzheimer's disease and multiple sclerosis. ${ }^{78} 79$ This signalling pathway also plays a role in RGC death and optic nerve degeneration in GLAST KO mice, ${ }^{80}$ and post-ONI treatment with a p38 MAPK inhibitor injected into the eyeball was effective for RGC protection. ${ }^{27}$ These results suggest that edaravone stimulates neuroprotection and may be useful for the treatment of glaucoma and post-traumatic complications.

In $\mathrm{DBA} / 2 \mathrm{~J}$ mice, oral administration of nicotinamide, the precursor of nicotinamide adenine dinucleotide and a key molecule in energy and redox metabolism, modulated mitochondrial vulnerability and prevented glaucoma in aged mice. ${ }^{24} 37$ Nicotinamides have been used for many years in the attempted treatment of a variety of disorders, including pellagra and skin diseases. ${ }^{81}{ }^{82}$ Moreover, amlexanox, a clinically approved TBK1 inhibitor used to treat bronchial asthma and allergic rhinitis, protected RGCs in optineurin E50K knock-in mice. ${ }^{49}$ These are relatively safe drugs and may be useful for the treatment of glaucoma (table 2).

In addition to the existing drugs, we are interested in the possibility that dairy food intake is positively related to neuroprotection. Spermidine is a natural component of our diet, and it is abundant in soybeans, mushrooms and so on. Spermidine is defined as a cationic polyamine, which exists in living cells and has been found to reduce the ageing process, at least partly, via autophagy activation. ${ }^{83}$ We previously reported that spermidine in drinking water prevented RGC death following ONI and in EAAC1 KO mice by reducing oxidative stress levels in the retina. ${ }^{62}{ }^{84}$ Interestingly, spermidine inhibited activation of the ASK1-p38 MAPK pathway in RGCs and suppressed the expression of inducible nitric oxide synthase in microglia following ONI. ${ }^{6284}$ Spermidine may also stimulate optic nerve axon regeneration after ONI. ${ }^{84} 85$ These findings indicate that the oral intake of spermidine and its antioxidative effects are beneficial in the treatment of glaucoma and that the beneficial effects of spermidine can be easily attained by making conscious food choices. We also reported that every-other-day fasting (EODF), a form of caloric restriction, increased histone acetylation and elevated expression levels of neurotrophic factors and catalase, whereas it decreased oxidative stress levels in the retina. ${ }^{86}$ Consistently, EODF attenuated NTG-like retinal degeneration in EAAC1
KO mice in both the histological and functional aspects. Our findings suggest that caloric restriction, a safe, non-invasive and low-cost treatment, may be available as an auxiliary measure for a long-term therapy of glaucoma as well as other age-related eye diseases. ${ }^{8788}$

We are also interested in the development of new drugs that have neuroprotective effects. As mentioned above, deletion of the ASK1 gene prevents RGC death in various mouse models of glaucoma, including retinal ischaemia, ONI and GLAST KO mice (GLAST/ASK1 double KO mice). ${ }^{27} 8089$ Together with recent studies demonstrating that an ASK1 inhibitor may be useful for patients with non-alcoholic steatohepatitis and kidney diseases,${ }^{90}$ our results suggest ASK1 inhibitors may be a good candidate for glaucoma. ${ }^{7879}$ On the other hand, Dock3 is an atypical guanine exchange factor for Rac1, which is specifically expressed in the central nervous system, ${ }^{91}$ and its expression level is decreased in the brain of patients with Alzheimer's disease. ${ }^{92}$ We found that overexpression of Dock3 protected RGCs in GLAST KO mice. ${ }^{93} 94$ Interestingly, Dock3 binds to GluN2B, one of the subunits for NMDA receptors, and reduces NMDA receptor expression leading to RGC protection. ${ }^{93}{ }^{94}$ In addition, overexpression of Dock3 stimulates optic nerve regeneration by stimulating multiple pathways. ${ }^{95-97}$ Thus, we are now trying to find a Dock3 activator that may be useful for neuroprotection and axon regeneration in Alzheimer's disease and glaucoma.

We believe that the various animal models of glaucoma previously mentioned should be available for future preclinical research to test these drugs, as well as any other new drugs.

\section{CONCLUDING REMARKS AND FUTURE PERSPECTIVES}

For glaucoma treatment, a strategy other than IOP reduction is required. We believe that neuroprotection is a promising alternative method and that animal models are useful for testing new therapies and pharmacological interventions, including drug repositioning. Pathogenesis of glaucoma is complex, and it involves multiple factors. Therefore, it is impossible for one animal model to satisfy all aspects of the disease. Moreover, when one of the factors is singled out, its contribution to pathogenesis may not necessarily be critical; for example, one should be aware that an animal model that possesses the same gene mutation as patients with glaucoma only represents a small percentage of total patients with glaucoma. In reality, the majority of glaucoma cases are sporadic and independent of genetic factors. This indicates that animal models whose pathogenesis is based on non-genetic factors, such as ageing and oxidative stress, are also significant and useful. In addition, there are fundamental anatomical and structural differences between mice and humans, for example, mice do not possess a lamina cribrosa or a macula. Therefore, it is unreasonable to expect that mouse models reproduce the same neurodegenerative patterns, namely, regional specificity of RGC loss or of visual field loss as observed in human glaucoma.

It is important to note that these animal models must be easy to use in practice, and this is a critical point to recognise for reviewers of scientific journals and research grants, as well as for scientists and medical doctors conducting experiments. In this respect, animal models that do not show $100 \%$ disease onset, have a lengthy disease course, or require extensive training for generation of disease may not be suitable from the reproducibility point of view and for clinicians and young researchers who, in recent years, have shown an increased tendency to leave research. However, research using disease models are essential for preclinical studies and for elucidating disease pathology, and 
one would expect its value will remain unchanged. For example, recent advances in technologies using iPS cells could generate RGCs, but interaction between RGCs and the surrounding cells will not be reconstructed and, if a whole eye is generated, studying the effects of the blood flow and the entire body on the generated eye would be difficult.

Findings from studies using high IOP models are naturally useful for NTG and so employing findings from NTG models together with findings from high IOP treatments could lead to development of novel treatments targeting non-IOP factors. Furthermore, in addition to developing better and 'more useful' mouse models, establishment of non-human primate models is a challenge for the future. All in all, understanding the pros and cons of individual disease models and using them appropriately for advances in basic research will lead to producing clinically useful outcomes. There is no doubt that this is a common goal for everyone.

Acknowledgements We apologise if we have omitted pertinent references due to a limited space.

Contributors All the authors wrote the manuscript, prepared the figure and tables, and read and approved the manuscript.

Funding This work was supported by JSPS KAKENHI JP16K11308 (CH), JP17K07123 (AK), JP16K07076 (XG), JP16K08635 (KN), JP15H04999 and JP18K19625 (TH), the Mitsui Life Social Welfare Foundation and the Takeda Science Foundation (TH).

Competing interests None declared.

Patient consent Not required.

Provenance and peer review Not commissioned; externally peer reviewed.

Open access This is an open access article distributed in accordance with the Creative Commons Attribution Non Commercial (CC BY-NC 4.0) license, which permits others to distribute, remix, adapt, build upon this work non-commercially, and license their derivative works on different terms, provided the original work is properly cited, appropriate credit is given, any changes made indicated, and the use is non-commercial. See: http://creativecommons.org/licenses/by-nc/4.0

\section{REFERENCES}

1 Resnikoff S, Pascolini D, Etya'ale D, et al. Global data on visual impairment in the year 2002. Bull World Health Organ 2004;82:844-51. https://scielosp.org/scielo.php?script=sci_ arttext\&pid=S0042-96862004001100009\&lng=en\&nrm=iso\&tlng=en

2 Pascolini D, Mariotti SP. Global estimates of visual impairment: 2010. Br J Ophthalmol 2012;96:614-8.

3 Quigley HA, Broman AT. The number of people with glaucoma worldwide in 2010 and 2020. Br I Ophthalmol 2006:90:262-7.

4 Luu J, Palczewski K. Human aging and disease: lessons from age-related macular degeneration. Proceedings of the National Academy of Sciences 2018;115:2866-72.

5 Promelle V, Daouk J, Bouzerar R, et al. Ocular blood flow and cerebrospinal fluid pressure in glaucoma. Acta Radiol Open 2016;5:2058460115624275.

6 Gherghel D, Griffiths HR, Hilton EJ, et al. Systemic reduction in glutathione levels occurs in patients with primary open-angle glaucoma. Invest Ophthalmol Vis Sci 2005;46:877-83.

7 Gherghel D, Mroczkowska S, Qin L. Reduction in blood glutathione levels occurs similarly in patients with primary-open angle or normal tension glaucoma. Invest Ophthalmol Vis Sci 2013;54:3333-9.

8 Goyal A, Srivastava A, Sihota R, et al. Evaluation of oxidative stress markers in aqueous humor of primary open angle glaucoma and primary angle closure glaucoma patients. Curr Eye Res 2014;39:823-9.

9 Kimura A, Namekata K, Guo X, et al. Targeting oxidative stress for treatment of glaucoma and optic neuritis. Oxid Med Cell Longev 2017;2017:1-8.

10 Seki M, Lipton SA. Targeting excitotoxic/free radical signaling pathways for therapeutic intervention in glaucoma. Prog Brain Res 2008;173:495-510.

11 Osborne NN, del Olmo-Aguado S. Maintenance of retinal ganglion cell mitochondrial functions as a neuroprotective strategy in glaucoma. Curr Opin Pharmacol 2013;13:16-22.

12 Gupta V, You Y, Li J, et al. BDNF impairment is associated with age-related changes in the inner retina and exacerbates experimental glaucoma. Biochim Biophys Acta 2014;1842:1567-78

13 Ren R, Jonas JB, Tian G, et al. Cerebrospinal fluid pressure in glaucoma: a prospective study. Ophthalmology 2010;117:259-66.
14 Jonas JB, Ohno-Matsui K, Panda-Jonas S. Optic nerve head histopathology in high axial myopia. J Glaucoma 2017;26:187-93. https://insights.ovid.com/pubmed?pmid=27846047

15 Suh SY, Le A, Shin A, et al. Progressive deformation of the optic nerve head and peripapillary structures by graded horizontal duction. Invest Ophthalmol Vis Sci 2017;58:5015-21. https://iovs.arvojournals.org/article.aspx?articleid=2656877

16 Janssen SF, Gorgels TG, Ramdas WD, et al. The vast complexity of primary open angle glaucoma: disease genes, risks, molecular mechanisms and pathobiology. Prog Retin Eye Res 2013:37:31-67.

17 Levin LA, Peeples P. History of neuroprotection and rationale as a therapy for glaucoma. Am J Manag Care 2008;14(1 Suppl):S11-14.

18 Tian K, Shibata-Germanos S, Pahlitzsch M, et al. Current perspective of neuroprotection and glaucoma. Clin Ophthalmol 2015;9:2109-18.

19 Gossman CA, Christie J, Webster MK, et al. Neuroprotective strategies in glaucoma. Curr Pharm Des 2016;22:2178-92.

20 Cheung W, Guo L, Cordeiro MF. Neuroprotection in glaucoma: drug-based approaches. Optom Vis Sci 2008;85:E406-16.

21 Semba K, Namekata K, Guo X, et al. Renin-angiotensin system regulates neurodegeneration in a mouse model of normal tension glaucoma. Cell Death Dis 2014;5:e1333.

22 Kimura A, Guo X, Noro T, et al. Valproic acid prevents retinal degeneration in a murine model of normal tension glaucoma. Neurosci Lett 2015;588:108-13.

23 Akaiwa K, Namekata K, Azuchi Y, et al. Edaravone suppresses retinal ganglion cell death in a mouse model of normal tension glaucoma. Cell Death Dis 2017;8:e2934.

24 Williams $\mathrm{PA}$, Harder JM, Foxworth $\mathrm{NE}$, et al. Vitamin $\mathrm{B}_{3}$ modulates mitochondrial vulnerability and prevents glaucoma in aged mice. Science 2017;355:756-60.

25 McKinnon SJ, Schlamp CL, Nickells RW. Mouse models of retinal ganglion cell death and glaucoma. Exp Eye Res 2009;88:816-24.

26 Johnson TV, Tomarev SI. Rodent models of glaucoma. Brain Res Bull 2010;81:349-58

27 Katome T, Namekata K, Guo X, et al. Inhibition of ASK1-p38 pathway prevents neural cell death following optic nerve injury. Cell Death Differ 2013;20:270-80.

28 Kimura A, Namekata K, Guo X, et al. Valproic acid prevents NMDA-induced retinal ganglion cell death via stimulation of neuronal TrkB receptor signaling. Am J Pathol 2015; 185:756-64.

29 Harada T, Harada C, Watanabe M, et al. Functions of the two glutamate transporters GLAST and GLT-1 in the retina. Proc Nat/ Acad Sci U S A 1998:95:4663-6.

30 Cone FE, Gelman SE, Son JL, et al. Differential susceptibility to experimental glaucoma among 3 mouse strains using bead and viscoelastic injection. Exp Eye Res 2010;91:415-24

31 Morrison JC, Cepurna WO, Johnson EC. Modeling glaucoma in rats by sclerosing aqueous outflow pathways to elevate intraocular pressure. Exp Eye Res 2015;141:23-32.

32 Shimazawa M, Nakamura S, Miwa M, et al. Establishment of the ocular hypertension model using the common marmoset. Exp Eye Res 2013;111:1-8.

33 Fernandes KA, Harder JM, Williams PA, et al. Using genetic mouse models to gain insight into glaucoma: past results and future possibilities. Exp Eye Res 2015;141:42-56.

34 John SW, Smith RS, Savinova OV, et al. Essential iris atrophy, pigment dispersion, and glaucoma in DBA/2J mice. Invest Ophthalmol Vis Sci 1998;39:951-62.

35 Turner AJ, Vander Wall R, Gupta V, et al. DBA/2J mouse model for experimental glaucoma: pitfalls and problems. Clin Exp Ophthalmol 2017;45:911-22.

36 Wang J, Dong Y. Characterization of intraocular pressure pattern and changes of retinal ganglion cells in DBA2J glaucoma mice. Int I Ophthalmol 2016;9:211-7.

37 Williams PA, Harder JM, John SWM. Glaucoma as a metabolic optic neuropathy: making the case for nicotinamide treatment in glaucoma. J Glaucoma 2017;26:1161-8. https://insights.ovid.com/pubmed?pmid=28858158

38 Leopold SA, Zeilbeck LF, Weber G, et al. Norrin protects optic nerve axons from degeneration in a mouse model of glaucoma. Sci Rep 2017;7:14274.

39 Seitz R, Hackl S, Seibuchner T, et al. Norrin mediates neuroprotective effects on retinal ganglion cells via activation of the Wnt/B-catenin signaling pathway and the induction of neuroprotective growth factors in Müller cells. J Neurosci 2010;30:5998-6010.

40 Fujikawa K, Iwata T, Inoue K, et al. VAV2 and VAV3 as candidate disease genes for spontaneous glaucoma in mice and humans. PLoS One 2010;5:e9050.

41 Shinozaki Y, Kashiwagi K, Namekata K, et al. Purinergic dysregulation causes hypertensive glaucoma-like optic neuropathy. JCI Insight 2017;2:e93456.

42 Iwase A, Suzuki Y, Araie M, et al. The prevalence of primary open-angle glaucoma in Japanese: the Tajimi Study. Ophthalmology 2004;111:1641-8.

$43 \mathrm{Kim} \mathrm{JH}$, Kang SY, Kim NR, et al. Prevalence and characteristics of glaucoma among Korean adults. Korean J Ophthalmol 2011;25:110-5.

44 Rezaie T, Child A, Hitchings R, et al. Adult-onset primary open-angle glaucoma caused by mutations in optineurin. Science 2002;295:1077-9.

45 Maruyama $\mathrm{H}$, Morino $\mathrm{H}$, Ito $\mathrm{H}$, et al. Mutations of optineurin in amyotrophic lateral sclerosis. Nature 2010;465:223-6.

46 Chi Z-L, Akahori M, Obazawa M, et al. Overexpression of optineurin E50K disrupts Rab8 interaction and leads to a progressive retinal degeneration in mice. Hum Mol Genet 2010;19:2606-15.

47 Meng Q, Xiao Z, Yuan H, et al. Transgenic mice with overexpression of mutated human optineurin(E50K) in the retina. Mol Biol Rep 2012;39:1119-24. 
48 Tseng HC, Riday TT, McKee C, et al. Visual impairment in an optineurin mouse model of primary open-angle glaucoma. Neurobiol Aging 2015;36:2201-12.

49 Minegishi Y, Nakayama M, lejima D, et al. Significance of optineurin mutations in glaucoma and other diseases. Prog Retin Eye Res 2016;55:149-81.

50 Minegishi Y, lejima D, Kobayashi H, et al. Enhanced optineurin E50K-TBK1 interaction evokes protein insolubility and initiates familial primary open-angle glaucoma. Hum Mol Genet 2013;22:3559-67.

51 Aung T, Ebenezer ND, Brice G, et al. Prevalence of optineurin sequence variants in adult primary open angle glaucoma: implications for diagnostic testing. J Med Genet 2003:40:101e-101.

52 Park J, Kim M, Park CK, et al. Molecular analysis of myocilin and optineurin genes in Korean primary glaucoma patients. Mol Med Rep 2016;14:2439-48.

53 Huang C, Xie L, Wu Z, et al. Detection of mutations in MYOC, OPTN, NTF4, WDR36 and CYP1B1 in Chinese juvenile onset open-angle glaucoma using exome sequencing. Sci Rep 2018;8:4498.

54 Harada T, Harada C, Nakamura K, et al. The potential role of glutamate transporters in the pathogenesis of normal tension glaucoma. J Clin Invest 2007;117:1763-70.

55 Osborne NN. Recent clinical findings with memantine should not mean that the idea of neuroprotection in glaucoma is abandoned. Acta Ophthalmol 2009:87:450-4.

56 Naskar R, Vorwerk CK, Dreyer EB. Concurrent downregulation of a glutamate transporter and receptor in glaucoma. Invest Ophthalmol Vis Sci 2000;41:1940-4. https://iovs.arvojournals.org/article.aspx?articleid=2123446

57 Ready T. Stiff penalty for vision researcher guilty of scientific misconduct. Nat Med 2001;7:8.

58 Ishikawa M, Yoshitomi T, Izumi Y. Excitotoxicity and glaucoma. In: Davey P, ed. Ophthalmology - current clinical and research updates. London: IntechOpen, 2014: 523-42

59 Ju WK, Kim KY, Angert M, et al. Memantine blocks mitochondrial OPA1 and cytochrome c release and subsequent apoptotic cell death in glaucomatous retina. Invest Ophthalmol Vis Sci 2009;50:707-16.

60 Atorf J, Scholz M, Garreis F, et al. Functional protective effects of long-term memantine treatment in the DBA/2J mouse. Doc Ophthalmol 2013;126:221-32.

61 Reichelt W, Stabel-Burow J, Pannicke T, et al. The glutathione level of retinal Müller glial cells is dependent on the high-affinity sodium-dependent uptake of glutamate. Neuroscience 1997:77:1213-24.

62 Noro T, Namekata K, Azuchi Y, et al. Spermidine ameliorates neurodegeneration in a mouse model of normal tension glaucoma. Invest Ophthalmol Vis Sci 2015;56:5012-9.

63 Akaiwa K, Namekata K, Azuchi Y, et al. Topical ripasudil suppresses retinal ganglion cell death in a mouse model of normal tension glaucoma. Invest Ophthalmol Vis Sc 2018;59:2080-9.

64 Shiga Y, Akiyama M, Nishiguchi KM, et al. Genome-wide association study identifies seven novel susceptibility loci for primary open-angle glaucoma. Hum Mol Genet 2018:27:1486-96

65 Dong XX, Wang Y, Qin ZH. Molecular mechanisms of excitotoxicity and their relevance to pathogenesis of neurodegenerative diseases. Acta Pharmacol Sin 2009:30:379-87.

66 Pérez de Lara MJ, Santano C, Guzmán-Aránguez A, et al. Assessment of inner retina dysfunction and progressive ganglion cell loss in a mouse model of glaucoma. Exp Eye Res 2014;122:40-9.

67 Schaub JA, Kimball EC, Steinhart MR, et al. Regional retinal ganglion cell axon loss in a murine glaucoma model. Invest Ophthalmol Vis Sci 2017;58:2765-73.

68 Nakano N, Ikeda HO, Hasegawa T, et al. Neuroprotective effects of VCP modulators in mouse models of glaucoma. Heliyon 2016;2:e00096.

69 Semba K, Namekata K, Kimura A, et al. Brimonidine prevents neurodegeneration in a mouse model of normal tension glaucoma. Cell Death Dis 2014;5:e1341.

70 Dong Z, Shinmei Y, Dong Y, et al. Effect of geranylgeranylacetone on the protection of retinal ganglion cells in a mouse model of normal tension glaucoma. Heliyon 2016;2:e00191

71 Shibuya E, Meguro A, Ota M, et al. Association of Toll-like receptor 4 gene polymorphisms with normal tension glaucoma. Invest Ophthalmol Vis Sci 2008:49:4453-7.
72 Takano Y, Shi D, Shimizu A, et al. Association of Toll-like receptor 4 gene polymorphisms in Japanese subjects with primary open-angle, normal-tension, and exfoliation glaucoma. Am J Ophthalmol 2012;154:825-32.

73 Todd L, Zelinka C. Valproic acid for a treatment of retinitis pigmentosa: Reasons for optimism and caution. J Neurosci 2017;37:5215-7.

74 Iraha $S$, Hirami Y, Ota $S$, et al. Efficacy of valproic acid for retinitis pigmentosa patients: a pilot study. Clin Ophthalmol 2016;10:1375-84.

75 Colman A, Dreesen O. Induced pluripotent stem cells and the stability of the differentiated state. EMBO Rep 2009;10:714-21.

76 Tanaka T, Yokoi T, Tamalu F, et al. Generation of retinal ganglion cells with functional axons from human induced pluripotent stem cells. Sci Rep 2015;5:8344.

77 Akiyama G, Azuchi Y, Guo X, et al. Edaravone prevents retinal degeneration in adult mice following optic nerve injury. Invest Ophthalmol Vis $\mathrm{SC}$ 2017:58:4908-14

78 Guo X, Harada C, Namekata K, et al. Regulation of the severity of neuroinflammation and demyelination by TLR-ASK1-p38 pathway. EMBO Mol Med 2010;2:504-15.

79 Guo X, Namekata K, Kimura A, et al. ASK1 in neurodegeneration. Adv Biol Regul 2017;66:63-71.

80 Harada C, Namekata K, Guo X, et al. ASK1 deficiency attenuates neural cell death in GLAST-deficient mice, a model of normal tension glaucoma. Cell Death Differ 2010;17:1751-9.

81 Knip M, Douek IF, Moore WPT, et al. Safety of high-dose nicotinamide: a review. Diabetologia 2000;43:1337-45.

82 Rolfe HM. A review of nicotinamide: treatment of skin diseases and potential side effects. J Cosmet Dermatol 2014;13:324-8.

83 Zheng Z, Wang Z-G, Chen Y, et al. Spermidine promotes nucleus pulposus autophagy as a protective mechanism against apoptosis and ameliorates disc degeneration. J Cell Mol Med 2018:22:3086-96.

84 Noro T, Namekata K, Kimura A, et al. Spermidine promotes retinal ganglion cell survival and optic nerve regeneration in adult mice following optic nerve injury. Cell Death Dis 2015;6:e1720.

85 Deng K, He H, Qiu J, et al. Increased synthesis of spermidine as a result of upregulation of arginase I promotes axonal regeneration in culture and in vivo. $J$ Neurosci 2009;29:9545-52.

86 Guo X, Kimura A, Azuchi Y, et al. Caloric restriction promotes cell survival in a mouse model of normal tension glaucoma. Sci Rep 2016;6:33950.

87 Kawashima M, Ozawa Y, Shinmura K, et al. Calorie restriction (CR) and CR mimetics for the prevention and treatment of age-related eye disorders. Exp Gerontol 2013;48:1096-100.

88 Anekonda TS. The benefits of calorie restriction and calorie restriction mimetics as related to the eye. Open Longev Sci 2009;3:28-37.

89 Harada C, Nakamura K, Namekata K, et al. Role of apoptosis signal-regulating kinase 1 in stress-induced neural cell apoptosis in vivo. Am J Pathol 2006;168:261-9.

90 Liles JT, Corkey BK, Notte GT, et al. ASK1 contributes to fibrosis and dysfunction in models of kidney disease. J Clin Invest 2018. in press.

91 Namekata K, Enokido Y, Iwasawa K, et al. MOCA induces membrane spreading by activating Rac1. J Biol Chem 2004;279:14331-7

92 Kashiwa A, Yoshida $\mathrm{H}$, Lee $\mathrm{S}$, et al. Isolation and characterization of novel presenilin binding protein. J Neurochem 2000;75:109-16.

93 Namekata K, Kimura A, Kawamura K, et al. Dock3 attenuates neural cell death due to NMDA neurotoxicity and oxidative stress in a mouse model of normal tension glaucoma. Cell Death Differ 2013;20:1250-6.

94 Kimura A, Namekata K, Guo X, et al. Dock3-NMDA receptor interaction as a target for glaucoma therapy. Histol Histopathol 2017;32:215-21.

95 Namekata K, Harada C, Taya C, et al. Dock3 induces axonal outgrowth by stimulating membrane recruitment of the WAVE complex. Proc Natl Acad Sci U S A 2010;107:7586-91.

96 Namekata K, Harada C, Guo X, et al. Dock3 stimulates axonal outgrowth via GSK-3ßmediated microtubule assembly. J Neurosci 2012:32:264-74.

97 Namekata K, Kimura A, Kawamura K, et al. Dock GEFs and their therapeutic potential: Neuroprotection and axon regeneration. Prog Retin Eye Res 2014;43:1-16. 